\title{
Parental Attitude on Children's after-school Physical Activity Participation: Lesson from a Pilot Study 兒童課後體能活動試驗計劃
}

\author{
Peggy PY CHEUNG \\ Department of Health and Physical Education \\ The Hong Kong Institute of Education, Hong Kong
}

張佩儀

香港教育學院健康與體育學系

\begin{abstract}
Parental influence on children's physical activity (PA) have been widely studied, however, limited study was reported particularly about after-school hours. The purposes of this study were: 1) to describe the changes of children PA during an after-school PA pilot program; 2) to explore parental attitudes on children's after-school PA participation. A 6-week afterschool PA pilot program was conducted in one primary school with a group of seven children (aged 8-10). The program content included both academic (i.e., tutorial session) and PA (i.e., organized PA session) components. Quantitative data on children's PA level during the after-school program was measured by pedometers. Qualitative data on parents of the participating children was collected through focus group meeting. The PA component of the program guaranteed children PA level during the after school hours. With the observed positive change on their child's behavior, academic performance, still remain the major concerns of parents for allowing children to involve in PA. The pilot program included a combination of PA and academic component satisfied the concern of parents. The findings can add information for future intervention design to increase the PA level of children during after-school hour.
\end{abstract}

\section{摘 要}

本文透過六星期的試驗計劃, 介紹一個以功課輔導及體能活動為主題的課後活動之結果, 並闡述家長對兒童參加課後活動的 意見。

\section{Introduction}

Global recommendations on physical activity (PA) indicate that children should accumulate at least 60 minutes of moderate to vigorous physical activity (MVPA) daily (World Health Organization [WHO], 2010). The inadequacy of children's PA participation has been highlighted in international and domestic studies. Only $29 \%$ of high school students in the United States (Centre for Disease Control and Prevention, 2011) and $15.7 \%$ of children in Hong Kong were reported to have adequate PA for an average of at least 60 minutes per day (Department of Health, 2009). Schools seem to be a good venue for promoting PA participation since children spend many hours daily in school. There have been reports on schoolbased physical education (PE) intervention with some success in promoting children's PA (McMurray et al., 2002; Rudolf, Sahota, Barth, and Walker, 2001). However, 
it has been noted that schools are under pressure to reduce the time allocated to physical education (DuBose et al., 2008). In the local context, primary schools generally allocate only two 35-minute lessons per week to $\mathrm{PE}$, which in turn limits the opportunity for PA participation. Scheduling time for $\mathrm{PA}$ is essential to the overall health of children.

Recent studies suggested that after-school programs provide an ideal channel for promoting children's PA as it is conducted within a structured environment. (Trudeau and Shephard, 2005) These after-school programs were carried out within one of the largest blocks of discretionary time in a child's day (Pate, et al., 2006). Moreover, the after-school period was described as a "critical hour", with activity within that period reported to be representative of the overall activity level of young people (Hager, 2006; Mota, et al., 2003). Additionally, children were reported to engage in larger amount of PA during the after-school period (Prochaska, Sallis, Griffith, and Douglas, 2002; Sirard, Riner, McIver, and Pate, 2005).

Parental influence is an important social determinant in supporting children's PA participation (Sallis, Prochaska, and Taylor, 2000; Springer, Kelder, and Hoelscher, 2006). Previous studies confirmed the role of parental influence on their child's PA participation (Cheung and Chow, 2010; Welk, Wood, and Morss, 2003). Parental influence on children's PA can come in many different forms; these include being a role model ( Welk et al., 2003), direct facilitation (Robbins, Stommel, and Hamel, 2008), involvement (Ornelas, Perreira, and Ayala, 2007) and encouragement (King, Tergerson, and Wilson, 2008; Welk et al., 2003). After-school hours however are an unsupervised time in which parents are not able to be directly involved in, or monitor, their child's activities. Hence, the effect and means of parental influence on their children's PA may somewhat differ to that in other times of the day such as when their children are at home or during weekends. Parents' rules regarding PA and lack of parental support were perceived by children as obstacles to after-school PA participation (Stanley, Boshoff, and Dollman, 2013). In addition, parental attitudes on school performance were reported as the major barrier for children to have PA (Davison, 2009). In addition, the demand of parental supervision of children's homework has placed constraints on parents' ability to arrange afterschool PA for their child. As there are limited studies on the topic of parental attitudes towards after-school PA, a study on children after-school PA participation with the inclusion on parental attitudes will provide more insights for the planning of after-school PA programs. As a result, a large scale study has been designed aiming to examine this issue and to investigate the efficacy of an after-school PA promotion program among primary school children. This is the pilot study of the proposed large scale study with the following purposes: 1) to describe the changes of children PA during an after-school PA pilot program; 2) to explore parental attitudes on children's after-school PA participation. It aims to address the following research questions:

1. What effects will an after-school PA program composed of academic and PA components have on children's PA levels?

2. What are parental concerns regarding children's participation in the after-school PA program?

3. Are there any differences in parental views on children's after-school PA participation before and after the six-week pilot PA program?

\section{Methods}

The present study involved a mixed method design to address the research questions. A six-week after-school program with tutorial and PA components was piloted. Quantitative data was obtained to examine the efficacy of the pilot program on children's PA levels. Qualitative data was obtained using focus groups to examine parental attitude on children's participation in the after-school program.

\section{Participants}

Primary school children were recruited as the participants of this pilot program. Inclusion criteria for participation were: 1) children studying in year three and; 2) did not join any sport-related after-school program in the academic year of the pilot program. Considering the ratio between the instructor and participants so that each participant could receive close monitoring on the tutorial and PA sessions, the quota for the program was set to seven. Notices of invitation for program enrollment were sent to potential students in one primary school to recruit voluntary participants to the program. The notice included 
the invitation of one parent who is the prime caretaker of the participating children to attend focus group interviews conducted before and after the pilot program. Eventually seven children were enrolled in the program with their parent agreeing to participate in the interview.

\section{Instruments}

\section{Children's PA level during the pilot program}

The children's PA level during the after-school program was collected by using a pedometer (SW700, Yamax). Participants were instructed to clip the pedometer to the right side of the waist anterior to the mid-thigh, and to wear it at all times during the afterschool program. A log sheet was used to record the time allocation and steps recorded on the after-school program. The step counts of tutorial session (ST) and PA session (SPA) was computed for the whole pilot program and weekly steps were averaged for analysis.

\section{Parental views on children after-school PA participation}

A 60-minute focus group meeting with the parents was conducted before and after the pilot program. Each focus group meeting was conducted with discussion questions formulated from a main theme and started with an introductory question about children afterschool participation. The meeting was conducted with the researcher as the moderator to facilitate discussion. An assistant was present to take notes, record and transcribe the discussion for analysis.

\section{Procedure}

Pre-pilot phase. The children and their parents were invited to attend a briefing session before the commencement of the after-school program. During the briefing session, further explanation on the program objectives and implementation procedures were delivered to the participants followed by their written informed consent. The research assistant collected the child participants' anthropometric measures (i.e., height, weight, skinfold measurement) and the first focus group meeting was then conducted.
The main theme guided the discussion was "parents' perception of children after-school PA". The focus group discussion started with an introductory question "Do you think your child has adequate daily PA?" and followed with semi-structured discussion questions shown below:

What are the key factors affecting your choice of after-school activity for your child?

Does "sport" be one of the activity types in your child's after-school activity?

What are the major concerns in arranging afterschool activity for your child?

The pilot of the program. The design of the program was focused on the utilization of the after-school hours with content including both academic (i.e., tutorial session) and PA (i.e., structure PA session) components. The program was conducted in a 2-hour session during the after-school period for six weeks in the 2nd semester of the academic year (i.e., April to May). As it was a school-based PA program, classes were suspended during school holiday. An instructor with a physical education background was trained to conduct the program of both sessions.

Each session of the program started with the tutorial session, in which children were required to first individually complete their homework within 60-minutes. When all participants finished their homework, the PA session commenced. Participants who had completed homework before the end of the first 60 -mintures were allowed to self-study or have leisure activity, such as reading books or playing chess.

The PA session was conducted following the sequence of i) 5-minute warm up, ii) 45-minute main activities and iii) 10-minute cool down. The main activities included 15 minutes of traditional sports activities, such as rope skipping, basketball, table tennis and 30-minutes of physical games. The design of the physical games was based on the conceptual constructs (Enjoyment of PA, Belief of PA, Competence in PA and Peer Involvement) derived from the Youth Physical Activity Promotion Model (YPAP) (G. Welk, 1999) with the aims of promoting long term PA participation. There were 30 physical game activities that integrated the YPAP constructs in different sessions. Activity reports including the time required to complete homework and steps taken during the after-school program was sent to the parents for review weekly. 
Post-pilot phase. The participants and their parents were invited to attend a conclusion session one week after the completion of the program. During the session, children's anthropometric measurements and parent's focus groups was conducted in the same manner as in the prepilot stage.

The main theme guiding the discussion was "parents' view on the pilot after-school program" The introductory question was "Did your child talk to you about the program?" and followed with semi-structured discussion questions, including the following:

What are major changes in your child after the program?

How can the program benefit your child?

Will you allow your child to participate the program in the future?

\section{Data Analysis}

Quantitative data collected during the pilot study was analyzed using the Statistical Package for the Social Sciences (SPSS), version 21.0. Mean, standard deviations, and medians of the anthropometric measures were calculated for different phases of the program as well as for the step counts and duration of activities for different sessions (i.e., tutorial session vs PA session) of each week. Due to the small sample size, quantitative data could only be analyzed descriptively. Comparisons of the step counts and duration of activities between different sessions were conducted using Nonparametric Wilcoxon Sign Ranks test with related samples. The same also applied to the anthropometric measures between different phases of the program. A type I error rate of 5\% was used for all tests of hypotheses.
Qualitative data collected from the focus group sessions were transcribed and entered into NVIVO (QRS International, NVIVO 10.0). A researcher read and re-read the transcripts three times and noted down the ideas to get familiar with the data. An open-coding of data was first made by a research assistant and followed by a second round of coding using thematic analysis by the researcher. The coding was conducted to identify the themes arising from the focus group discussions. Members check was made by the participants to review their interpretation of the findings after the focus group meetings. A thematic analysis approach was used to analyze the transcript data. Subscales were triangulated to the themes made from the note in focus groups.

\section{Results}

\section{Participants' PA level during the pilot program}

Seven children participated in the pilot study (4 boys, 3 girls; mean age $=8.71, \mathrm{SD}=.76$ ). All children were in grade three at one local primary school in Hong Kong. At the pre and post phases, participants' anthropometric measures were collected, including body height and weight, from which body mass index (BMI) was derived. Skinfold measurement was obtained for the calf and triceps using a skinfold caliper. Participants' physiological variables were presented in Table 1. Comparisons of these variables between pre-and-post phases suggested no significant difference $(p>0.05)$

Table 1. Mean (S.D.) and Median of Anthropometric Measures of Participants in Pre-and-post Phases (n=7)

\begin{tabular}{lll}
\hline & pre-pilot phase & post-pilot phase \\
\hline Body Height $(\mathrm{cm})$ & $137.9(6.54) ; 135$ & $140.6(8.65) ; 137.0$ \\
Body weight $(\mathrm{kg})$ & $34.6(7.28) ; 35$ & $35.0(7.70) ; 36.0$ \\
BMI & $18.2(3.94) ; 18.6$ & $17.7(3.61) ; 18.9$ \\
Skinfold* $(\mathrm{mm})$ & $31.00(8.1) ; 29.0$ & $27.1(6.6) ; 24.0$ \\
\hline
\end{tabular}

* sum of calf and triceps measurement 
The program was conducted for six weeks. As there were four days of school holidays during the program period, the pilot program consisted of a total of 26 activity days. During the 2 hour program, the mean step counts for the PA session were 6,284 steps in comparison to 914 steps for the tutorial session $(\mathrm{p}<0.05)$. As shown in Table 2, the weekly step counts recorded during the after-school period increased progressively from week 1 to week 6 for both PA and tutorial sessions with the overall major activity level recorded as $87.3 \%$. Significant differences were observed on step counts between sessions for each week $(\mathrm{p}<0.001)$.

Table 2. Mean (S.D.) and Median of Weekly Step Counts and Duration of Activities by Different Sessions (n=7)

\begin{tabular}{ccccc}
\hline & \multicolumn{2}{c}{$\begin{array}{c}\text { Activity record } \\
\text { during PA Session }\end{array}$} & \multicolumn{2}{c}{$\begin{array}{c}\text { Activity record } \\
\text { during Tutorial Session }\end{array}$} \\
\hline & \multicolumn{2}{c}{ Step counts } & Minutes & \multicolumn{2}{c}{ Step counts } & Minutes \\
& \multicolumn{2}{c}{ Mean (S.D.) $;$ median } & & Mean (S.D.) $)$ median \\
\hline Week 1 & $4445(1853) ; 3856$ & $56.2(10.0) ; 60$ & $498(534) ; 261$ & $63.8(10.0) ; 60$ \\
Week 2 & $5638(2419) ; 5517$ & $59.3(10.7) ; 60$ & $875(1017) ; 625$ & $60.7(10.7) ; 60$ \\
Week 3 & $5678(3064) ; 5166$ & $58.8(9.78) ; 60$ & $909(776) ; 743$ & $61.3(9.8) ; 60$ \\
Week 4 & $6488(4084) ; 5410$ & $61.6(19.3) ; 60$ & $984(1648) ; 475$ & $58.4(19.2) ; 60$ \\
Week 5 & $7243(3131) ; 6465$ & $65.9(19.2) ; 65$ & $899(722) ; 684$ & $54.1(19.2) ; 55$ \\
Week 6 & $8193(3881) ; 7323$ & $66.8(20.6) ; 70$ & $1321(824) ; 1020$ & $53.2(20.6) ; 50$ \\
\hline Average & $6284(3363) ; 5609$ & $61.4(15.9) ; 60$ & $914(989) ; 684$ & $58.6(15.9) ; 60$ \\
\hline
\end{tabular}

\section{Parents' View on Children's After-school PA Participation}

Six prime care-takers (4 mothers and 2 grandmothers) participated in the two focus group meetings. One parent was unable to participate due to work commitments.

\section{Pre-pilot Focus Group}

Referring to the introductory question, all parents agreed that their children did not have an adequate amount of daily PA. The main reason was because they spent too much time on their homework,

"When my kid gets back home, he needs to do homework, watches $T V$, and then has dinner. He doesn't have time to do exercise".

"My child needs a long time to finish homework, and left no time to do exercise."
Academic concern was another major theme that emerged from the discussion on after-school activity. All parents supported the idea that involvement in exercise was good to their children,

"In fact, after the long day of study, children need to take some exercise such as playing basketball, swimming, etc"

"My kid likes dancing, I will allow her to take the dance class on Saturday."

However, parents perceived academic performance as a more important concern.

"If he scored lower mark in the exam, I will stop his participation in the activity class"

"In order not to distract his focus, he had to stop the activity class during examination period, except tuition class." 


\section{Post-pilot Focus Group}

After the completion of the program, all parents agreed that their children enjoyed the program. The children were willing to talk to their parents about the program,

"My girl talked to me about the games that she played during the program everyday"

"My boy is very excited even back home and wants more time to play."

Regarding the organization of the program, academic concern was still a primary focus of parents on afterschool activity, and this was followed by social support as a secondary concern.

"It is better to have more time spent on revision of the teaching materials.

"I feel comfortable that the children is supervised in school"

Health outcomes were another theme that emerged after the implementation of the program. All parents observed changes in their children after the program, including better sleep, better appetite and more time left for academic revision.

"He is stronger, may be because of playing basketball during the program"

"He now eats more and he looks happier"

"In the past, he went to bed at 9:00pm and felt asleep at around 10:00pm. Now, he falls asleep in a minute after go to bed."

"It is easier to wake him up in the morning, may be, it is because he slept earlier at night time".

\section{Discussion}

The purpose of this study is to describe the result of an after-school PA program. A promising finding was that children were engaged in a higher level of PA during the after-school hours. The after-school program was featured with the inclusion of a combination of academic and PA components. The incorporation of a PA session guaranteed children's engagement in PA. Within the 2-hour after-school program, children were more active in the PA session than in the tutorial session $(6,284$ steps vs 914 steps). This finding further supports the importance of arranging organized PA to enhance children PA participation.
Previous studies indicated that during unsupervised after-school hours, children engaged in sedentary activity for half of the time (Cheung, 2012). Technology-based sedentary behavior (i.e., TV viewing, computer and video game use), and homework were behaviors most prevalent (Atkin, et al., 2008; Rushovich et al., 2006). Elementary school children in Hong Kong were reported to spend 170 minutes on completing homework assignments daily (Tam and Chan, 2009). On the other hand, the participation in organized PA allowed children to engage more time on vigorous PA and less time on sedentary activities (Cheung, 2012). Other studies also pointed out that the total PA level of adolescents can be accrued through organized activities (Santos, Esculcas, and Mota, 2004). Although the Education Bureau in Hong Kong has launched school-or community-based after-school programs, the main purpose of the core activity remains on the enhancement of learning effectiveness. Shifting some of the time spent on academic to organized PA participation would definitely be useful to enhance children's overall PA participation. The after-school PA program demonstrated that without direct parental supervision and facilitation, the provision of an organized PA program under school supervision was a practical and possible means to increase children's PA levels.

Another purpose of the study was to explore parental attitudes on children's after-school PA participation. The qualitative data acquired from the parents' perspective provided more information on the design of afterschool programs for children. Parents in the current study perceived good grades as a higher priority than being physically active. However, they are also willing to support children's PA participation under the condition when there was no need to sacrifice academic pursuits. In the local context, the after-school period is considered as an extension of education. The pursuit of academic performance was prevalent with $72.2 \%$ of primary school students receiving private tutoring (Youth Research Centre, 2013). Their parents also spend 36.98 minutes assisting and supervising children's homework. More importantly, "parents' request" was one of the reasons that children had private tutoring. The expectation of good academic performance is a major outcome of tutorial group participation. Similar to previous studies, parents' perception of children school performance was the major barrier for children's PA (Davison, 2009). The perception about the adverse effect of PA on academic achievement affected parental arrangements on the types of activity during the after-school period. With 
the over-emphasis on academic excellence, parents often place a higher priority on academic achievement than on recreational pursuits (Yu, et al., 2006). The view on the importance of academic achievement is deeply rooted in local society, which is not easy to change.

From another perspective, information on the parent's recognition of the changes to children's health behavior, including better sleep, better appetite and more time left for academic revision is encouraging. The program was able to provide comparable differences on children's behavior, which may shed some light on the direction of how to educate parents on the importance of PA. It is possible to modify the belief that PA and homework are mutually exclusive activities. Changing the parental perception on the importance of PA would, therefore, be an important direction. To encourage parents in making a choice to balance the academic achievements and health of their children would then be an alternative strategy.

There are a few limitations to this study that future research should attempt to alleviate. Because this was a pilot study, the design involved only one school with a small size of seven students. In the full study, the sample size should be based on a proper calculation based on information gathered from this pilot study. The present study did not account for the influence of significant others, such as peers and close friends, which may also affect children's PA participation. Future studies can focus on the dynamics of these relationships in order to identify appropriate strategies to promote children's PA. In terms of the measurement of PA, this pilot study only used the pedometer as the PA measure. Other objective measurement tool, such as tri-axial accelerometer and activity $\log$ can collect more information on child's PA during the after-school hours.

\section{Conclusions}

This pilot study provided some indicative evidence in supporting the after-school program with the strategy of including "academic" and "PA" components. The tutorial sessions satisfy the parental concern of children's academic performance, while the PA sessions cater to the need of children to play and have fun. The full study could draw reference from present findings and utilize an experimental design with the inclusion of a control group and larger sample size to examine the effectiveness of the program.

\section{References}

Atkin, A. J., Gorely, T., Biddle, S. J. H., Marshall, S. J., \& Cameron, N. (2008). Critical hours: Physical activity and sedentary behavior of adolescents after school. Pediatric Exercise Science, 20, 446-456.

Centre for Disease Control and Prevention. (2011). Youth risk behavior Surveillance-United states 2011. MMWR CDC Surveillance Summary. 2012, 61(SS-4)

Cheung, P. Y. (2012). Association of after-school physical activity levels and organized physical activity participation in Hong Kong children. European Physical Education Review, 18(2), 182-190.

Cheung, P. Y., \& Chow, B. C. (2010). Parental mediatory role in Children's physical activity participation. Health Education, 110(5), 351-366.

Davison, K. K. (2009). School performance, lack of facilities, and safety concerns: Barriers to parents' support of their children's physical activity. American Journal of Health Promotion, 23(5), 315-319.

Department of Health. (2009). Child Health Survey 200506. Hong Kong: The Department ; 2009.

DuBose, K. D., Mayo, M. S., Gibson, C. A., Green, J. L., Hill, J. O., \& \& Jacobsen, D. J. (2008). Physical activity across the curriculum (PAAC): Rationale and design. Contemporary Clinical Trials, 29(1), 83-93.

Hager, R. L. (2006). Television viewing and physical activity in children. The Journal of Adolescent Health, 39(5), 656-661.

King, K. A., Tergerson, J. L., \& Wilson, B. R. (2008). Effect of social support on adolescents' perceptions of and engagement in physical activity. Journal of Physical Activity and Health, 5(3), 374-384.

McMurray, R. G., Harrell, J. S., Bangdiwala, S. I., Bradley, C. B., Deng, S., \& Levine, A. (2002). A school-based intervention can reduce body fat and blood pressure in young adolescents. Journal of Adolescent Health, $31,125-132$.

Mota, J. P., Santos, S., Guerra, J. C., \& Ribeiro, J. D. (2003). Patterns of daily physical activity during school days in children and adolescents. American Journal of Human Biology, 15(4), 547-553. 
Ornelas, I. J., Perreira, K. M., \& Ayala, G. X. (2007). Parental influences on adolescent physical activity: A longitudinal study. International Journal of Behavioral, Nutrition and Physical Activity, 4(3)

Pate, R. R., Stevens, J., Pratt, C., Sallis, J. F., Schmitz, K. H., Webber, L. S., \& Welk, G. (2006). Objectively measured physical activity in sixth-grade girls. Archives of Pediatrics \& Adolescent Medicine, 160, 1262-1268.

Prochaska, J. J., Sallis, J. F., Griffith, B., \& Douglas, J. (2002). Physical activity levels of barbadian youth and comparison to a U.S. sample. International Journal of Behavioral Medicine, 9, 360-372.

Reverter, J., Montero, D., Hernandez, V., Jové, C., \& Coiduras, J. (2013). Parental attitudes towards extracurricular physical and sports activity in schoolage children. Journal of Human Sport \& Exercise, $8(3), 861-876$.

Robbins, L. B., Stommel, M., \& Hamel, L. M. (2008). Social support for physical activity of middle school students. Public Health Nursing, 25(5), 451-460.

Robinson, T. N. (2001). Television viewing and childhood obesity. Pediatric Clinics of North America, 48, 1017-1025.

Rudolf, C. J., Sahota, S., Barth, J. H., \& Walker, J. (2001). Increasing prevalence of obesity in primary school children: Cohort study. British Medical Journal, 322, 1094-1095.

Rushovich, B. R., Voorhees, C. C., Davis, C. E., Neumark-Sztainer, D., Pfeiffer, K. A., Elder, J. P., \& Marino, V. G. (2006). The relationship between unsupervised time after school and physical activity in adolescent girls. The International Journal of Behavioral Nutrition and Physical Activity, 3, 20.

Sallis, J. F., Prochaska, J. J., \& Taylor, W. C. (2000). A review of correlates of physical activity of children and adolescents. Medicine and Science in Sports and Exercise, 32, 963-975.

Santos, M. P., Esculcas, C., \& Mota, J. (2004). The relationship between socioeconomic status and adolescents' organized and nonorganized physical activities. Pediatric Exercise Science, 16, 210-218.

Sirard, J. R., Riner, W. F., McIver, K. L., \& Pate, R. R. (2005). Physical activity and active commuting to elementary school. Medicine and Science in Sports and Exercise, 37, 2062-2069.
Springer, A., Kelder, S., \& Hoelscher, D. (2006). Social support, physical activity and sedentary behavior among 6th grade girls: A cross-sectional study. International Journal of Behavioral, Nutrition and Physical Activity, 3(8)

Stanley, R. S., Boshoff, K., \& Dollman, J. (2013). A qualitative exploration of the "critical window": Factors affecting Australian children's after-school physical activity. Journal of Physical Activity \& Health, 10(1), 33-41.

Tam, V. C., \& Chan, R. M. (2009). Parental involvement in primary children's homework in Hong Kong. The School Community Journal, 19(2), 81-100.

Trudeau, F., and Shephard, RJ. (2005). Contribution of school programmes to physical activity levels and attitudes in children. Sports Medicine, 35(2), 89-105.

Welk, G. J., Wood, K., \& Morss, G. (2003). Parental influences on physical activity in children: An exploration of potential mechanisms. Pediatric Exercise Science, 15(1), 19-33.

Welk, G. (1999). The youth physical activity promotion model: A conceptual bridge between theory and practice. Quest, 5l(1), 5-23.

World Health Organization [WHO]. (2010). Global recommendations on physical activity for health. ().World Health Organization, UNICEF.

Yasmin, A., Heather, M., Katherine, R., Patti-Jean, N., Teresa, L., and Heather, M. (2007). School-based physical activity does not compromise children's academic performance. Medicine and Science in Sports and Exercise, 39(2), 371-376.

Youth Research Centre. (2013). Private tutoring of students in Hong Kong. Youth Hong Kong, 5(1), 39-41.

Yu, CCW., Chan, S., Cheng, F., and Sung, RYT. (2006). Are physical activity and academic performance compatible? Academic achievement, conduct, physical activity and self-esteem of Hong Kong Chinese primary school children. Education Studies, 32(4), 331-341.

\section{Correspondence}

Dr. Peggy Cheung

Department of Health and Physical Education,

The Hong Kong Institute of Education,

Tai Po, Hong Kong.

Email: cheungpy@ied.edu.hk 